\title{
Simulation of the Service Center for Vehicles on Liquefied Petroleum Gas \\ ${ }^{1}$ Larisa M. Gabsalikhova, ${ }^{2}$ Irina V. Makarova, ${ }^{3}$ Polina A. Buyvol, ${ }^{4}$ Vadim G. Mavrin, ${ }^{5}$ Ksenia A. Shubenkova \\ ${ }^{1-5}$ Kazan Federal University \\ Email: skyeyes@mail.ru
}

Received: 23 ${ }^{\text {rd }}$ July 2019, Accepted: 10 ${ }^{\text {th }}$ August 2019, Published: 31 ${ }^{\text {st }}$ August 2019

\begin{abstract}
The purpose of the research is developing tools for forecasting changes in the service system when expanding the fleet of gas-engine vehicles. Research objectives: consideration methods for reducing emissions of harmful substances in exhaust gases of motor vehicles, consideration the features of the organization of technological processes in the service system when launching vehicles with alternative fuel to the market, developing a simulation model of a service center specializing in the repair and maintenance of diesel and gas vehicles. The following research methods were used: methods of system analysis and mathematical statistics, simulation. Three groups of measures aimed at reducing harmful substances in vehicle exhaust gases are described. It is shown that the usage of gas as an alternative fuel has good prospects for reducing the load on the environment. Achieved results: the developed simulation model can be used to conduct a computer experiment to select the optimal parameters for the operation of an auto service enterprise serving vehicles on both conventional diesel and compressed natural gas.
\end{abstract}

\section{Keywords}

Branded Service Network, Safety, Vehicles on Gas, Environmental Friendliness, Maintenance.

\section{Introduction}

Accelerated motorization in addition to the increase in population mobility entails negative consequences that have an increasing impact on human health and cause new risks. Toxic substances released during the operation of automobile engines are one of the main causes of urban air pollution. Toxic emissions of vehicles are exhaust gases, crankcase gases and fuel vapors from the fuel tank, with the majority of them being exhaust gases.

The composition of engines exhaust gases depends on the group and fractional composition of the fuel used, the nature of the additives contained in the fuel, the type of organization and the perfection of the working process, the operating conditions, the technical condition, etc. The most unfavorable modes of operation are low speeds and "idling" of the engine, when pollutants are released into the atmosphere in quantities far exceeding the emission under load conditions. The technical condition of the engine directly affects the environmental performance of emissions. The exhaust gases of a gasoline engine with improperly adjusted ignition contain carbon monoxide (II) in an amount 2 to 3 times higher than normal.

Harmful substances contained in the exhaust gases of vehicles, entering the environment, can interact with its components, which leads to the formation of secondary pollution, an example of which is photochemical smog.

The formation of photochemical smog involves hydrocarbons and nitrogen oxides contained in the exhaust gas; main components of smog are ozone and peroxyacyl nitrates, which have pronounced toxic properties.

Currently, in Russia there is a wide range of assessments of atmospheric pollution from $25 \%$ to $80 \%$. The lower limit is typical for its overall balance, the upper limit is for the largest administrative centers or for territories with a practical absence of industrial enterprises. According to expert estimates, in more than 150 cities of Russia, it is motor transport that has the predominant effect on air pollution.

\section{Methods}

Measures for reducing emissions of harmful substances in the vehicles' exhaust can be divided into three groups.

The first group of activities is related to the improvement of the design of engines and vehicles, the improvement of the quality of fuel. It includes:

- the improvement of the ignition system, including equipment with contactless ignition systems;

- changing the processes of fuel supply to engine cylinders, including the use of electronic fuel injection;

- ensuring the recycling of exhaust gases, as well as the installation of microprocessor engine control systems;

-the usage of gasolines and diesel fuel of high environmental purity, characterized by an optimal fractional composition and low sulfur content, benzene, aromatic hydrocarbons;

-the usage of alternative, environmentally friendly types of motor fuels. Alternative fuels include fuels of non-petroleum origin, such as compressed natural gas, the main component of which is methane, ethanol, hydrogen, biofuel. In the near future, hydrocarbon gaseous fuels can make a real alternative to traditional petroleum fuels (gasoline and diesel fuels). They are compressed natural gas and liquefied petroleum gases. When engines operate on hydrocarbon gaseous fuels, a higher degree of combustion of fuels is provided, which leads to a reduction in emissions of CO, nitrogen oxides, non-methane hydrocarbons, and solid particles with exhaust gases. Natural gas, associated gas from gas, gas condensate and oil fields, as well as biomethane, which can be obtained from agricultural and industrial waste, can be used as a motor fuel, which contributes to the expansion of the resource base and the transition to renewable sources of raw materials; 
-the usage of electric vehicles, electric buses [1,2]. Electric vehicles have a fairly low drag coefficient. This is achieved due to the absence of holes in the body for cooling the engine. This also leads to a decrease in aerodynamic noise - the less sharp corners on the body, at which airflow can disrupt, the less wind noise. Electric vehicles can also reduce tire noise. Since electric motors have a smoother traction characteristic of torque, compared with internal combustion engines, therefore, the transfer of torque to the wheels occurs smoothly, which almost eliminates the slippage of the tires when starting off. The advantage of this type of transport is that it is noiseless and environmentally friendly.

The second group of activities consists of organizational and technical measures, including:

- ensuring regular monitoring of the toxicity and opacity of exhaust gases of vehicles on urban and transit highways;

-imposition of restrictions on the movement of vehicles in certain lanes at certain hours of the day;

- route orientation of drivers;

-the formation of the park on the condition of non-exceedance of gross emissions (forecast of the number, structure of the park by age and type of fuel; assessment of gross emissions of harmful substances and the amount of fuel consumption by the park; adjustment of the number of vehicles)

- Equipment of a truck fleet with exhaust gas neutralization systems. Exhaust gas cleaning systems of engines are given in article [3].

The third group of activities includes:

- the choice of optimal urban solutions, including the construction of road intersections, underground crossings, the usage of circular traffic;

- re-planning of the traffic and its structure for a long-term period and individual hours of the day;

- creation of vehicle-free zones, primarily in the central part of cities;

- introduction of paid travel during peak hours to the urban areas with the highest traffic intensity;

- optimization of the stops of shuttle vehicles;

- the organization of the movement of vehicles using automated traffic control systems in combination with a system for monitoring air pollution;

- improving the efficiency of traffic lights;

- introduction of one-way traffic schemes. Thus, in the Japanese city of Osaka, after the introduction of one-way traffic, the tension on the roads significantly decreased, the average vehicle speed increased and, as a result, the emissions of pollutants into the atmosphere with exhaust gases decreased;

- partial prohibition of the movement of individual transport in certain areas of the city during periods of particularly adverse meteorological conditions $[4,5]$.

\section{Results and Discussion}

Currently, vehicle manufacturers try to improve the environmental friendliness and energy efficiency of vehicles. The reasons are due to the urbanization in emerging economies, the growth of motorization and its negative consequences, such as emissions of toxic substances and greenhouse gases [6,7], a decrease in the quality of life of the population, an increase in injuries and morbidity. According to the forecasts outlined in the UNEP report [8], by the year 2050 the world vehicle fleet will triple, almost all this growth will be in developing countries. Currently, transport accounts for: more than half of the world's consumption of liquid fossil fuels; almost a quarter of the $\mathrm{CO}_{2}$ emissions; more than $80 \%$ of air pollution in major cities; more than 1.27 million fatal traffic accidents annually; traffic jams in many cities around the world [9]. These costs of the society make up more than $10 \%$ of the gross domestic product and will grow, first of all, because of the expected growth of the world car fleet.

It is possible to reduce harmful effects on environment from trucks fleet by its renewal. In this case, we should give preference to more environmentally friendly and energy-efficient models [10]. Of all mass-used motor fuels and technologies, natural gas provides the safest emissions of exhaust gases and has less impact on lubricating oils. Thus, the convert of vehicles from gasoline to gas allows reducing by an average of five times the emissions of harmful substances, and the noise effect twice. And most importantly, the gas does not contain sulfur, which is the main pollutant of gasoline.

Natural gas is used in different forms: compressed natural gas (CNG), liquefied natural gas (LNG) and associated petroleum gas (APG) $[11,12]$. There are about 4 million vehicles with CNG in the world. CNG is widely distributed in countries with natural gas reserves. Such vehicles are suitable for use as public transport [13]. In some countries liquefied petroleum gas (LPG) is used for public transport. So according to the studies [14], in Japan, Italy and Canada, $7 \%$ of buses use LPG.

The main problem in introducing gas vehicles is the unpreparedness of the infrastructure to mass use of gas vehicles. A feature of gas vehicles is that they are need more frequent refueling. In turn it requires a more gas filling stations. In addition, it is necessary to expand or modernize the branded service network with workshops for service of gas equipment [15]. At the same time, the most important issue is the reliability of gas vehicles and the development of the branded service system, especially during the warranty period of operation [16].

The introduction of new models of vehicles to the markets, especially on alternative sources of fuel, may be associated with the need to change the technological process of carrying out maintenance and repair. Service autocenters can be created both on the premises of the new building and on the existing production areas of the operating enterprise. When creating plots on new premises, a promising option is the usage of frame-tent structures designed specifically for service centers. Since such projects require significant investments, it is necessary to pre-assess the risks, as well as the factors 
that will increase the efficiency of the service system $[17,18]$. This is important for branded service network because the competitiveness of a manufacturer and the brand trust depend strongly on the efficiency of service system [19, 20]. As structure of the fleet changes gradually, at the initial stage the more efficient solution will be the use of the existing branded service network. This decision is most reasonable for the reason that maintenance and repair of all units of natural gas vehicles, with the exception of the fuel supply system of natural gas vehicles, are performed in the same building for cars that run on liquid fuel (Fig. 1).

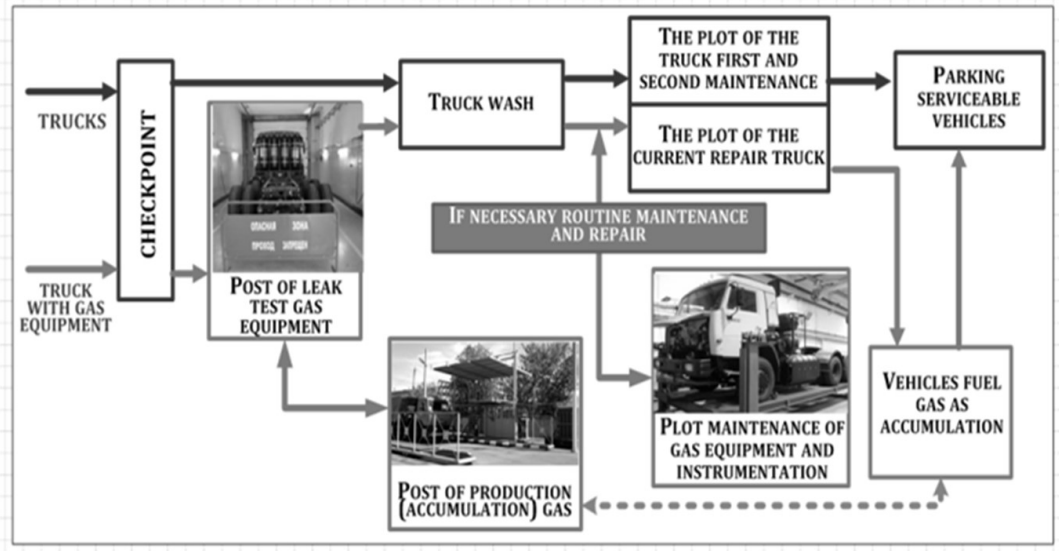

Figure 1: The Standard Scheme of Work on Maintenance and Repair of Gas Vehicles.

Taking into account that the main difference in the service of natural gas vehicles is due to the specificity of the engine and the type of fuel, for the development of the simulation model regulatory documents on the organization of technological processes for this type of vehicles were used. Failures distribution laws of the main components of the power unit, the fuel system and gas equipment, the frequency of appeals to the car dealer and other data were analyzed. The software package AnyLogic was chosen as a tool to develop a simulation model. The library of objects of discreteevent simulation - Enterprise Library - was used for developing the model.

Implemented in the model algorithm provides for the maintenance of a motor vehicle with both diesel and gas engines. In addition, there is a possibility of delays in repairs due to lack of spare parts (Fig. 2). At present, it is planned to expand the fleet of natural gas vehicles (in particular, garbage trucks and other municipal vehicles), as well as buses. This will allow to make the verification and validation of the model, as well as develop recommendations for the rational development of the system of branded automotive service.

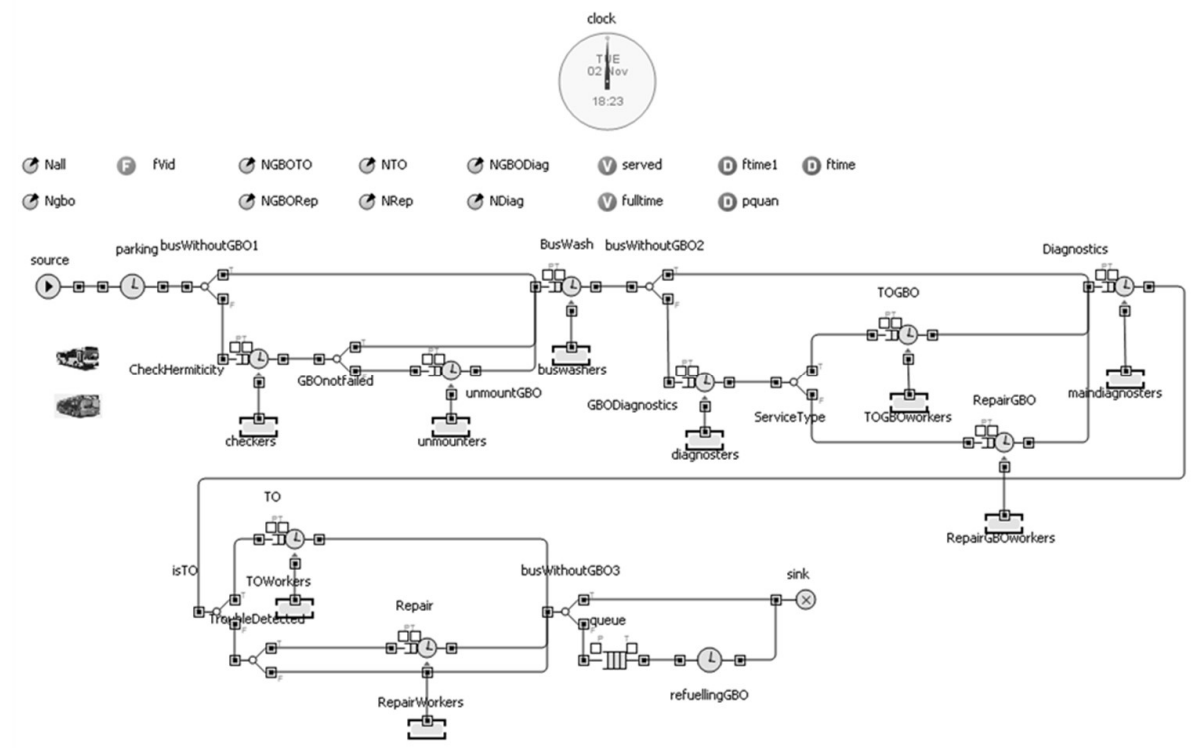

Figure 2: Structure of the Simulation Model.

\section{Summary}

Research has shown that only system solutions to reduce emissions of harmful substances in exhaust gases of motor vehicles will increase its competitiveness, as well as ensure the possibility of trouble-free operation. The implementation of the scientific approach to the improvement of the branded service system will enable to respond quickly to emerging problems when operating vehicles of the new model range.

The recent increase in interest in gas as automotive fuel is due to higher energy and environmental performance compared to petroleum fuels. The introduction of new models of vehicles on alternative fuel sources to the markets may 
be associated with the need to change both the technological process of maintenance and repair in a service center, and the branded service network as a whole.

\section{Conclusions}

Poor air quality, climate change, a lack of balance between society and the natural environment are increasingly affecting human health and causing new risks. One of the options for reducing the burden on the environment is the usage of road transport on alternative fuels. Expansion of the fleet due to gas-engine vehicles requires changes in the service system. Improving management through the development and usage of simulation models will make it possible to adjust measures aimed at the realization of strategic goals, at each stage, to choose the most rational option for each combination of the prevailing conditions.

\section{Acknowledgements}

The work is performed according to the Russian Government Program of Competitive Growth of Kazan Federal University.

\section{References}

[1] O. Vliet, A. S. Brouwer, T. Kuramochi, M. Broek, A.Faaij, "Energy use, cost and CO2 emissions of electric cars", Journal of Power Sources, vol. 196, iss. 4, pp. 2298-2310, 2011.

[2] C.E. Thomas, "Fuel cell and battery electric vehicles compared International", Journal of Hydrogen Energy , vol. 34 , iss. 15 , pp. 6005-6020, 2009.

[3] U. G. Alkemade, B. Schumann, "Engines and exhaust after treatment systems for future automotive applications", Solid State Ionics, vol. 177, iss. 26-32, pp. 2291-2296, 2006.

[4] Madrid imposes restrictions for vehicles on the basis of even and odd numbers. URL: https://news.rambler.ru/europe/35719350/?utm_content=rnews\&utm_medium=read_more\&utm_source=copylin $\mathrm{k}$.

[5] A city without a vehicle. URL: http://эко-вахта.pф/wp-content/uploads/2015/09/.

[6] E. Puliafito, "High resolution inventory of GHG emissions of the road transport sector in Argentina Salvador", Atmospheric Environment, vol. 101, pp. 303-311, 2015.

[7] L.G. Anderson, "Effects of using renewable fuels on vehicle emissions", Renewable and Sustainable Energy Reviews, vol. 47, pp.162-172, 2015.

[8] "Strategic Report: Environment, Peace and Security: A Convergence of Threats". URL: https://wedocs.unep.org/bitstream/handle/20.500.11822/17008/environment_peace_security.pdf? sequence=1\&is Allowed $=\mathrm{y}, 2016$.

[9] "INTERNATIONAL ENERGY OUTLOOK 2016 Report Number: DOE/EIA-0484". URL: https://www.eia.gov/outlooks/ieo/pdf/0484(2016).pdf, 2016.

[10] J.M. Bergthorson, M.J. Thomson, "A review of the combustion and emissions properties of advanced transportation biofuels and their impact on existing and future engines", Renewable and Sustainable Energy Reviews, vol. 42, pp. 1393-1417, 2015.

[11] E. Chikishev et. al., "Prospects of and Problems in Using Natural Gas for Motor Transport in RUSSIA", IOP Conference Series: Materials Science and Engineering, vol. 142, no. 1, 2016.

[12] Q. Zhuang, J. Yodotani, M. Kato, "Accurate measurement method for the residues in liquefied petroleum gas", Fuel, vol. 84, pp. 443-446, 2005.

[13] E. Chikishev et al., "Natural Gas Use On Minibuses, Engaged In The Carriage Of Passengers And Baggage On The Regular Routes, As A Measure For Decrease In Harmful Environment Effects", IOP Conference Series: Earth and Environmental Science, vol. 50, 2017.

[14] D. Sperling, "Future Drive_Electric Vehicles and Sustainable Transportation" Island Press, Washington, DC. 1995

[15] "UNIMOT GAZ will build a network of gas stations and lng regasification station". URL: http://www.unimot.pl/en/unimot-gaz-will-build-a-network-of-gas-stations-and-lng-regasification-station/.

[16] I. Makarova et al., "Prospects and Risks the Transfer of Motor Transport at the Gas Fuel", Journal of International Scientific Publications: Ecology and Safety, vol. 8. URL: http://www.scientific-publications.net.

[17] P.A. Buyvol, L.M. Gabsalikhova, I.V.Makarova, E.M. Mukhametdinov, G.R. Sadygova, "Improving the branded service network efficiency based on its functioning evaluation", Astra Salvensis, vol. 2017, pp. 373-385, 2017.

[18] P.A. Buyvol, L.M. Gabsalikhova, I.V. Makarova, E.M. Mukhametdinov, "Increase in the efficiency of the operation of vehicle inspection companies", Dilemas contemporaneos-educacion politica y valores, vol. 6 , article number: 90, 2018.

[19] I. Makarova et al., "Improving the system of warranty service of trucks in foreign markets", Transport Problems, vol. 10, iss. 1, pp. 63-78, 2015.

[20] I. Makarova et al., "Improving of performance system of warranty for automotive engineering abroad on the basis of data of rejections analysis". Innovative Mechanical Engineering Technologies, Equipment and Materials, vol. 69, 2014. 